\title{
Dynamics of information entropy of road safety provision systems in Siberian regions
}

\author{
Artur Petrov ${ }^{1, *}$ \\ ${ }^{1}$ Tyumen Industrial University, Volodarskogo str., 38, Tyumen, 625000, Russia
}

\begin{abstract}
This article considers the issues of dynamics of road safety provision systems in three multiscaled systems (Russia, Siberian Federal Okrug or SFO and separate regions of SFO). The indicator of relative information entropy $\mathrm{Hn}$ of road safety provision process was taken as the characteristic of system orderliness. The ideology, methodic and results of quantitative assessment of road safety provision systems information entropy $\mathrm{H}$ were considered. Time series of modification of relative information entropy $\mathrm{Hn}$ of road safety provision systems in 2004...2018 in Russia, Siberian Federal Okrug and individual subjects of SFD were presented. Special attention was paid to consideration of the re-searched process in the Republic of Tuva. This region is characterized by nonstandard, different from general trend dynamics of information entropy $\mathrm{H}$ of road safety provision system. The general conclusion of the article is that during last 15 years information entropy of road safety provision systems significantly decreased, i.e. orderliness of formation process of road traffic participants safety greatly increased. However, results achieved in this sphere by Siberian regions are still far from best world results.
\end{abstract}

\section{Introduction}

Management - transfer of manageable system from current state to desirable (i.e. complex of works on practical implementation of image of the future). During management activities structural and technological orderliness of system and its functioning process increases [1]. In other words, any management activity is intended to fight with entropy - process of growth of uncontrolled chaos in system. Quality of management can be accurately measured by evaluation of system entropy and dynamics of its decline.

\footnotetext{
* Corresponding author: ArtIgPetrov@yandex.ru
} 
State of any transport-technological system is described by enormous set of different characteristics that can be classified by various features (efficiency, quality of functioning, development speed, etc.) [2, 3]. While managing the system, it is necessary to control dozens of traffic parameters and adjust production process in time. It is a complex task. That is the reason of strict regulation of road traffic participants behavior (with the aim of formation of optimal low-entropy system state). It is supposed that such regulation will decrease the degree of chaos in transport-technological system and increase its reliability. For that purpose, system of restrictions imposed on participants of transport process - road traffic rules - has been widely used worldwide for a long time. Increasing of road safety is expressed in development of complex traffic light regulations and initiation of freedom limitation of road traffic participants.

Specifics of transport-technological systems consist in their non-stationarity, continuous variability and not full controllability. In this connection transport management is one of the most difficult types of management activities, entropy in transport systems is quite large.

One of the most demonstrative examples of transport systems' entropy is traffic accident rate that is presented only in negative way despite laws of dialectics. According to the estimations of World Health Organization [4] annually in the result of road accidents nearly $1,35 \mathrm{mln}$. people die, more than $30 \mathrm{mln}$. people get injured, economic loss because of road accident rate makes $\$ 550$ bln.

\section{Formulation of the problem}

Management by objectives is used for control of large systems. The distinctive feature of this method is clear understanding of cause-effect relationships, formulation of goals and development of constrained environment for management. Particularly in Russia such approach was formulated in the Russian Federation Target Federal Programme on road safety (for a period of 2013...2020) [5] and moved to the Road safety strategy in the Russian Federation for 2018-2024 [6].

But these documents only declare general directions of road safety development and don't formalize peculiar methods of solving designated problems. There is a variety of instruments that can provide road safety, they can be both engineering and juridical. Efficiency of their usage can be different in various regions of the Russian Federation. It can be explained by national and social-economical specifics of regions. In this connection state of road safety differently forms in each region. And still there is no tool for measurement the degree of road safety system orderliness. Taken analysis of this issue [1] showed that one of the most efficient instrument of evaluation of the system state from the position of orderliness or forwardness to opposition to negative impact of chaos is assessment of entropy.

This article presents ideology, method of quantitative assessment of information entropy in the road safety provision sphere and results of assessment of dynamics of relative entropy of road safety provision systems in regions of Siberian Federal Okrug.

\section{Main conceptsand definitions}

Fundamental concepts of this article are Orderliness and Information entropy. It is necessary to formulate their definitions. 
Orderliness - system property, identifying the result of implementation of set of rules and forbiddances that structure system and limit its modifications [7]. Orderliness is an antonym to chaos. Applied to road safety provision processes, orderliness decreases freedom of actions of road traffic participants and at the same time probability of violation or road traffic rules. That automatically leads to decline of probability of road accidents formation and enhancement of final road accidents statistics.

Information entropy - measure of uncertainty (disorganization) of system state [8]. The concept of information entropy, introduced by C.E. Shannon in his paper «A Mathematical Theory of Communication» [9], is a probability of some event. The less the probability of event, the more information it includes [1]. Applied to the assessment of orderliness of road safety provision processes, it means that if information entropy is low, then organizers of transport and technological process can guarantee safe functioning of the system. In the conditions of high uncertainty of system state, we can get set of possible outcomes, including undesirable (road accidents and their consequences).

\section{Methodic of quantitative assessment of information entropy in road safety provision sphere}

The main principles of this method were developed by authors of this article and had already been presented in earlier published works $[7,8,10]$. Moreover, results were showed at scientifically-practical conferences in Saint-Petersburg (2016 and 2018), in Oryol (2017...2019), in Moscow (2018), in Orenburg (2017), in Tyumen (2016...2019). Thereby main ideas of these methodic will be just mentioned in this article.

1. The process of road accident rate formation should be considered from the position of process of quantitative information transmission through the chain «Population - The number of vehicles - The number of road accidents - The number of victims - The number of deaths» (fig. 1). The scale of consideration or road accident formation process can differ: large (World, Continent), medium (Country, individual regions of country), small (city, district of city).

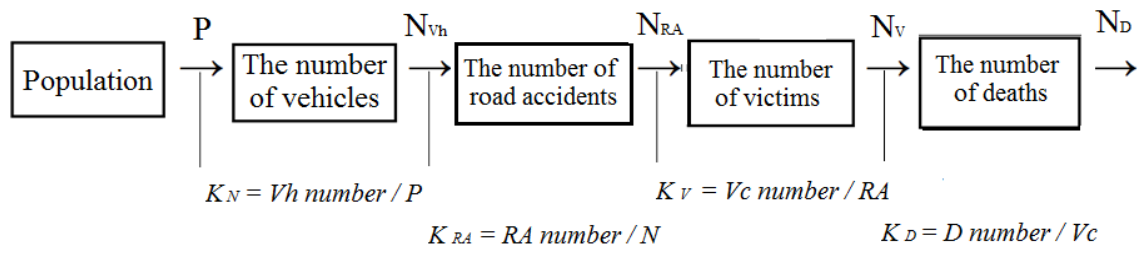

Fig. 1.The cause-effect chain of road accident rate formation [10].

2. Calculation of transition coefficients $K_{i}$ between blocks of the cause-effect chain of road accident rate formation (fig. 1). We will describe this process as 4 subprocesses that have specific coefficients $K_{N}$ (transformation of number of population into the number of transport vehicles in transport fleet), $K_{R A}$ (transformation of vehicle fleet into the number of road accidents), $K_{V}$ (transformation of the number of road accidents into the number of road accidents victims), $K_{D}$ (transformation of the number of road accidents victims into the number of lost in road accidents people).

3. Identifying of the positive of the contribution $Q$ relatively to weights of appropriate elements of examined transformational process within the chain «Population $-<\ldots>-$ The number of deaths in road accident» (1): 


$$
Q=Q_{N}+Q_{R A}+Q_{V}+Q_{D}=\ln \left(1 / K_{N}\right)+\ln \left(1 / K_{R A}\right)+\ln \left(K_{V}\right)+\ln \left(1 / K_{D}\right)
$$

The physical meaning of the positive of the contribution $Q$ of different elements of the chain «Population $-\langle\ldots\rangle-$ The number of deaths in road accident» into the final result of road accident rate is the measure of information amount or derivative of examined process entropy.

4. Identifying the structure of weight coefficients $w_{i}$ for assessing the positive of the contribution $Q$ of different elements of the chain «Population $-<\ldots>-$ The number of deaths in road accident». Availability of calculated values $w_{N}, w_{R A}, w_{V} w_{D}$ of positive allows to solve the main problem of entropic analysis - assess the impact of different elements of the chain «Population $-<\ldots>-$ The number of deaths in road accident» on formation of final road accident rate. Above-stated researches were held for each year from period of $2004 \ldots 2018$.

5. Calculation of entropy $H$ in road safety provision systems of Russian Federationand Siberian regions by classic C.E. Shannon's [9] formula (2):

$$
H=-\sum_{i=1}^{n} w_{i} \cdot \ln w_{i}
$$

where $\quad n \quad-\quad$ system elements count (in our case $n=4$ );

$$
\begin{aligned}
& w_{i}-\text { weight coefficients, satisfying the normalization condition, } \\
& \sum_{i=1}^{n} w_{i}=1 .
\end{aligned}
$$

6. Calculation of relative information entropy (3) of the road safety provision systems of the Russian Federation and Siberian regions:

$$
H_{n}=H / H_{\max }=H / \ln (n)
$$

Values of $H n$ varies in range from 0 to 1 , where 1 means total disorganization or process, while 0 indicates total orderliness and absence of the chaos in system. In reality entirely ordered or disordered systems and processes don't exist. Actual range of $H n$ values is $0.5 \ldots 0.9$ for the road safety provision sphere. For example, in Great Britain which has repressive road safety provision system $H n$ was a little bit less than 0.5 in 2015 [8]. And in some African countries $\mathrm{Hn}$ for road safety provision systems reaches $0.85 \ldots 0.9$.

\section{$5 \quad$ Initial data and results of calculation of relative entropy $\mathrm{Hn}$ of road safety provision systems in Russia, Siberia and in particular Republic of Tuva}

As mentioned above specific methods of assessment of human-technical systems orderliness were previously considered in [7, 8]. This article is presenting only results of estimation of relative entropy $H n$ of road safety provision systems in the Russian Federation, Siberia and in particular Republic of Tuva (during 2004...2018).

Tables 1...3 show initial data [11] and results of calculation of relative entropy $\mathrm{Hn}$ of road safety provision systems in the Russian Federation, Siberia and Republic of Tuva accordingly. 
Table 1. Initial data [11] that was used for analysis of road safety orderliness dynamics in the Russian Federation and results of calculation of relative entropy $\mathrm{Hn}$.

\begin{tabular}{|c|c|c|c|c|c|c|}
\hline Year & 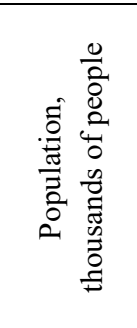 & 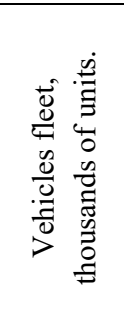 & 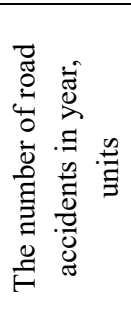 & 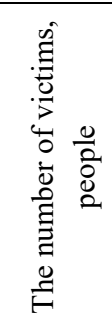 & 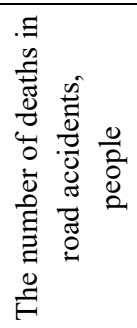 & 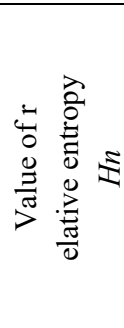 \\
\hline 2004 & 144168.2 & 29025.3 & 208558 & 284865 & 34506 & 0.789 \\
\hline 2005 & 143474.2 & 31087.6 & 223342 & 308821 & 33957 & 0.784 \\
\hline 2006 & 142753.6 & 34968.2 & 229140 & 318086 & 32724 & 0.781 \\
\hline 2007 & 142221.0 & 35885.3 & 233809 & 325514 & 33308 & 0.780 \\
\hline 2008 & 142008.8 & 38696.0 & 218322 & 300819 & 29936 & 0.768 \\
\hline 2009 & 141904.0 & 41206.4 & 203618 & 283143 & 27659 & 0.760 \\
\hline 2010 & 142856.5 & 42062.7 & 199431 & 277202 & 26567 & 0.757 \\
\hline 2011 & 142865.4 & 43325.3 & 199868 & 279801 & 27953 & 0.755 \\
\hline 2012 & 143030.1 & 45471.1 & 203597 & 286609 & 27991 & 0.751 \\
\hline 2013 & 143347.1 & 47881.8 & 204068 & 285462 & 27025 & 0.745 \\
\hline 2014 & 143666.9 & 49540.4 & 199720 & 278748 & 26963 & 0.739 \\
\hline 2015 & 146267.3 & 51591.9 & 184000 & 254311 & 23114 & 0.732 \\
\hline 2016 & 146544.7 & 54014.3 & 173694 & 241448 & 20308 & 0.727 \\
\hline 2017 & 146804.4 & 53500.0 & 169432 & 234462 & 19088 & 0.728 \\
\hline 2018 & 146880.4 & 53047.0 & 168099 & 233067 & 18214 & 0.730 \\
\hline
\end{tabular}

Table 2.Initial data [11] that was used for analysis of road safety orderliness dynamics in Siberia (Siberian Federal Okrug) and results of calculation of relative entropy $\mathrm{Hn}$.

\begin{tabular}{|c|c|c|c|c|c|c|}
\hline Year & 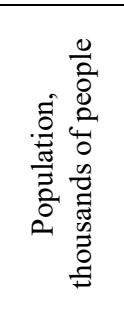 & 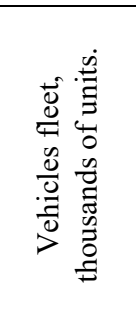 & 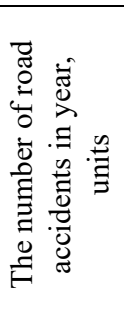 & 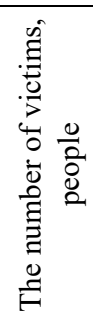 & 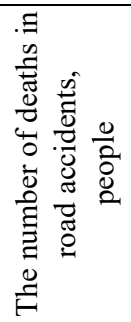 & 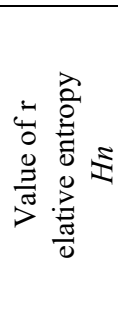 \\
\hline 2004 & 20166.0 & 4447.034 & 29922 & 40922 & 4735 & 0.782 \\
\hline 2005 & 20059.0 & 4497.435 & 29964 & 41389 & 4621 & 0.784 \\
\hline 2006 & 19941.0 & 4540.610 & 30482 & 42329 & 4365 & 0.787 \\
\hline 2007 & 19590.0 & 4262.354 & 30613 & 42896 & 4621 & 0.783 \\
\hline 2008 & 19553.5 & 5008.454 & 28945 & 40322 & 4284 & 0.773 \\
\hline 2009 & 19545.5 & 5333.475 & 26707 & 37562 & 3793 & 0.766 \\
\hline 2010 & 19561.0 & 5454.430 & 26448 & 36628 & 3642 & 0.761 \\
\hline 2011 & 19249.8 & 5647.632 & 27074 & 37996 & 3994 & 0.758 \\
\hline 2012 & 19254.3 & 5983.172 & 27905 & 39269 & 3964 & 0.754 \\
\hline 2013 & 19278.2 & 6282.635 & 28549 & 40153 & 3874 & 0.750 \\
\hline 2014 & 19312.2 & 7301.786 & 27125 & 37827 & 3640 & 0.727 \\
\hline 2015 & 19324.0 & 7301.786 & 26279 & 36224 & 3191 & 0.726 \\
\hline 2016 & 19326.2 & 7213.077 & 24787 & 34321 & 2628 & 0.730 \\
\hline 2017 & 19270.8 & 7391.820 & 23844 & 32891 & 2540 & 0.724 \\
\hline 2018 & 19222.3 & 7420.680 & 22927 & 31725 & 2456 & 0.722 \\
\hline
\end{tabular}


Table 3. Initial data [11] that was used for analysis of road safety orderliness dynamics in the Republic of Tuva and results of calculation of relative entropy $H n$.

\begin{tabular}{|c|c|c|c|c|c|c|}
\hline Year & 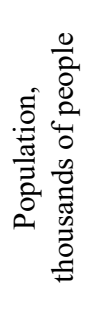 & 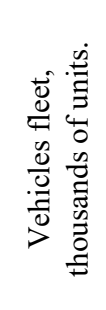 & 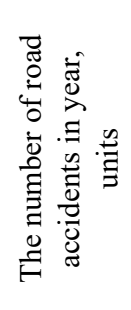 & 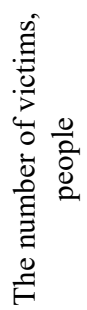 & 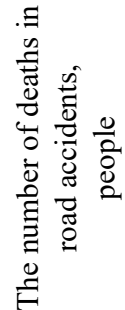 & 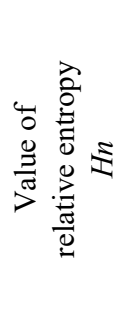 \\
\hline 2004 & 306.0 & 43.428 & 351 & 572 & 123 & 0.815 \\
\hline 2005 & 308.0 & 32.899 & 329 & 569 & 126 & 0.837 \\
\hline 2006 & 309.0 & 33.024 & 314 & 550 & 126 & 0.835 \\
\hline 2007 & 309.5 & 33.658 & 305 & 557 & 135 & 0.835 \\
\hline 2008 & 311.6 & 41.194 & 386 & 692 & 121 & 0.845 \\
\hline 2009 & 313.9 & 45.386 & 363 & 674 & 125 & 0.838 \\
\hline 2010 & 317.0 & 48.009 & 341 & 670 & 132 & 0.835 \\
\hline 2011 & 308.2 & 51.106 & 331 & 676 & 144 & 0.828 \\
\hline 2012 & 309.4 & 54.775 & 337 & 655 & 145 & 0.816 \\
\hline 2013 & 310.5 & 60.700 & 386 & 770 & 133 & 0.828 \\
\hline 2014 & 311.8 & 57.012 & 402 & 735 & 163 & 0.815 \\
\hline 2015 & 315.6 & 55.888 & 520 & 842 & 120 & 0.828 \\
\hline 2016 & 318.5 & 59.776 & 530 & 870 & 118 & 0.827 \\
\hline 2017 & 321.7 & 61.073 & 539 & 880 & 99 & 0.830 \\
\hline 2018 & 324.4 & 61.326 & 530 & 880 & 92 & 0.834 \\
\hline
\end{tabular}

\section{Estimation of dynamics of relative entropy $\mathrm{Hn}$ of road safety provision systems}

\subsection{Estimation of dynamics of relative entropy $\mathrm{Hn}$ of road safety provision systems in the Russian Federation and Siberia (Siberian Federal Okrug or SFO)}

Fig. 2 shows the trend of change of relative entropy or road safety provision systems in Russia and Siberia (Siberian Federal Okrug) in 2004...2018. Value of Hn decreases in both cases, therefore the degree of chaos declines in compared road safety provision systems and their orderliness increases.Processes of regulation of road safety provision system functioning in Russia and Siberia proceeds in parallel (fig. 2).

But in such big system as Russia the proceeding is smoother than in SFO where the process of entropy decline is characterized by greater oscillation amplitude. 


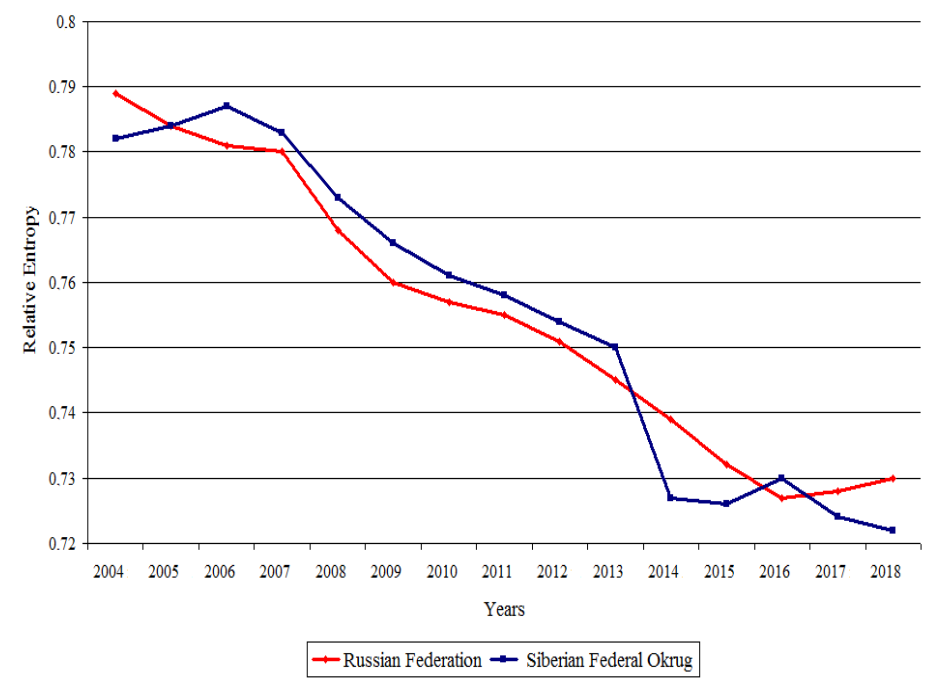

Fig. 2. Time series of modification of values of relative entropy $H n$ of road safety provision systems in the Russian Federation and Siberia (Siberian Federal Okrug).

\subsection{Estimation of dynamics of relative entropy $\mathrm{Hn}$ of road safety provision systems in the Siberian regions}

Fig. 3 shows the trend of change of relative entropy or road safety provision systems in the Siberian regions in $2004 \ldots 2018$.

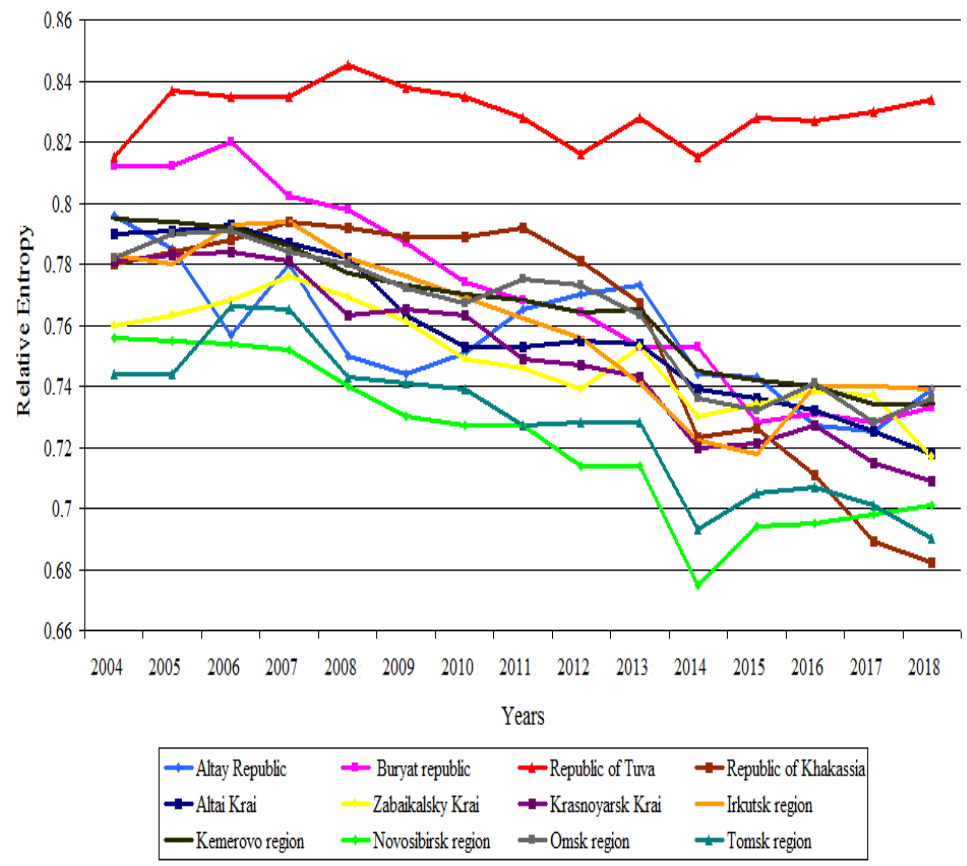

Fig. 3.Time series of modification of values of relative entropy $H n$ of road safety provision systems in the Siberian regions. 
Analysis of fig. 3 allows to understand that, despite regional specifics, practically in all regions, except Republic of Tuva, level of road safety provision system orderliness increases, because relative entropy $H n$ of road accident formation processes persistently decreases.

Among other Siberian regions the situation in road safety provision system of Tuva Republic arouses special interest (fig. 3).

The degree of orderliness in road safety provision sphere in this region has increased during $2004 \ldots 2018$.

Specialists of the General Administration for Traffic Safety of the Ministry of Internal Affairs of Russia should take control under situation in Republic of Tuva.

\section{Evaluation of dynamics of relative entropy $H n$ of road safety provision systems in the Siberian regions}

By approximation of time series of modification of value of relative entropy $\mathrm{Hn}$ of road safety provision systems in the Siberian regions during $2004 \ldots 2018$ by linear function $\mathrm{Hn}$ $=f$ (Years) we got values of parameter $b$ of model $H n=a-b$ (Years). Values of this parameter are presented in table 4.

Table 4. Quantitative values of parameter $b$ of model $H n=a-b$ (Years) for regions of the Siberian Federal Okrug.

\begin{tabular}{lcc}
\hline $\begin{array}{c}\text { Region of } \\
\text { Siberian Federal Okrug }\end{array}$ & $\begin{array}{c}\text { Quantitative values of } \\
\text { parameter } b \text { of model } \\
H n=a-b \text { (Years) }\end{array}$ & $\begin{array}{c}\text { Coefficient of model } \\
\text { determination } \mathrm{R}^{2}\end{array}$ \\
\hline Altay Republic & -0.0036 & 0.57 \\
Buryat republic & -0.0072 & 0.95 \\
Republic of Tuva & -0.0004 & 0.04 \\
Republic of Khakassia & -0.0078 & 0.73 \\
Altai Krai & -0.0055 & 0.95 \\
ZabaikalskyKrai & -0.0033 & 0.76 \\
Krasnoyarsk Krai & -0.0058 & 0.95 \\
Irkutsk region & -0.0049 & 0.77 \\
Kemerovo region & -0.0048 & 0.97 \\
Novosibirsk region & -0.0053 & 0.84 \\
Omsk region & -0.0046 & 0.85 \\
Tomsk region & -0.0049 & 0.80 \\
\hline
\end{tabular}

Analysis of quantitative values of parameter $b$ of model $H n=a-b$ (Years) specific for different Siberian regions allows to make conclusion about specifics of dynamics of growth of orderliness of regional road safety provision systems.

\section{Discussion of results}

According to the data from table 4 during the last 15 years $(2004 \ldots 2018)$ :

- The highest pace of growth of road safety provision system orderliness was in Republic of Khakassia ( $b=-0.0078$ or $0.78 \%$ in a year) and Buryat republic $(b=-0.0072$ or $0.72 \%$ in a year); 
- Relatively small growth of road safety provision systems orderliness was registered in Zabaikalsky Krai $(b=-0.0033$ or $0.33 \%$ in a year) and Altai Krai $(b=-0.0036$ or $0.36 \%$ in a year);

- In Republic of Tuva there is no changes in road safety provision systems orderliness sphere.

- In other Siberian regions changes of road safety provision systems orderliness equals to the range $[-0.0046 ;-0.0058]$ or $[-0.46 \%$ in a year; $-0.58 \%$ in a year];

- Considering established trends of dynamics of decreasing $H n(\approx 0.5 \%$ in a year $)$, nearly $30 \ldots 35$ years required in order to achieve the level of the best world practices of the road safety provision systems orderliness $(H n=0.50 \ldots 0.55)$.

\section{Conclusions}

In the Road safety strategy in the Russian Federation for 2018-2024 [6] the target for Human Risk for 2024 equals to 4 people/100 thousand people or in other words 6000 dead people in road accidents per year in the country with 150 million population. Is it an achievable goal?

Taking into account the decline of $H n$ by $0,5 \%$ per year during $2019 \ldots 2024$, it is expectable that $H n$ will decrease by $3 \%$ relatively to $H n_{R F 2018}=0.730$, i.e up to $\mathrm{Hn}_{R F} 2024$ $=0.708$. This level of dynamics of relative information entropy in road safety provision system of Russia will predict the value of the mortality rate in road accidents as approximately 16.5 thousand people per year. For achievement of ambitious plans, formulated in the Road safety strategy in the Russian Federation up to 2024, Hn should have been decreased by $5 \%$ per year. It is hardly possible. Most likely an intermediate result will be achieved.

\section{References}

1. E. Schrödinger, What is Life? The Physical Aspect of the Living Cell. (1944).

2. M. Koryagin, A. Dementiev, V. Sokolov, Transportation Research Procedia 36, 334-340 (2018).

3. V. R. Vuchic, Transportation for livable cities. (1999).

4. World Health Organization, https://www.who.int/news-room/detail/07-12-2018new-who-report-highlights-insufficient-progress-to-tackle-lack-of-safety-on-theworld's-roads, last accessed 2016/05/31.

5. Russian Federation Target Federal Programme on road safety (for a period of 2013...2020), http://www.fcp-pbdd.ru/about_program/,last accessed 2016/06/12.

6. Road safety strategy in the Russian Federation for 2018-2024, http://static.government.ru/media/files/g6BXGgDI4fCEiD4xDdJUwlxudPATBC12.pdf, last accessed 2016/06/12.

7. A. Petrov, V. Kolesov, IOP Conf. Series: Earth and Environmental Science, 177, 012015 (2018).

8. V. Kolesov, A. Petrov, Transportation Research Procedia 36, 286-294 (2018)

9. C. E. Shannon, Bell System Technical Journal 27, 379-423; 623-656 (1948).

10. V. Kolesov, A. Petrov, Transportation Research Procedia .20, 305-310 (2017).

11. State Inspection for Road Traffic Safety of the Ministry of Internal Affairs of Russia. https://www.gibdd.ru/stat/ last accessed 2019/06/22. 